\title{
Kinematic Synthesis of a Novel Type of the Series of Transmissions with Independently Controllable Output Speed
}

\author{
Damir Jelaska ${ }^{1, *}$, Srdjan Podrug ${ }^{2}$ and Milan Perkušić ${ }^{3}$ \\ ${ }^{1,2,3}$ University of Split, FESB, R. Boškovića 32, HR 21000 Split, Croatia \\ *Corresponding author: Tel.00385914305991; E-mail: djelaska@fesb.hr
}

\begin{abstract}
A power-split-type transmission with independently controllable output speed (ICTs) was recently proposed. It is capable of converting a variable or constant input shaft speed into a controllable output shaft speed independent of the input speed - without ordinary speed control system. However, this transmission has no practical significance, because of huge control motor power and uncontrollable speed of one output shaft. The novel type of the hybrid ICT is proposed in this paper that consists of three differential gear trains and two ordinary gear drives, with input shaft of arbitrary speed and three more external shafts with mutually controllable speeds. The kinematic synthesis of the series of the proposed type of ICTs is carried out. The numerical example, assigned to a vehicle, is demonstrated where a continuous variation of required vehicle speeds at arbitrary riding conditions is achieved without using a speed control system. For the optimal speed of driving engine, i.e. for minimum fuel consumption at any vehicle speed, the engine speed control system is provided, with control motor that runs at speed forcing engine to run at optimal speed.
\end{abstract}

\section{Keywords}

Differential gear train; Transmission feasibility; Compatibility function; Power circulation; Automotive transmission.

\section{Introduction}

In this age of energy crisis and increasing environmental concerns, energy savings have become an important topic. Over the past three decades, a variety of power technologies have been developed which have improved the energy conversion efficiency and its cost. Obtaining the low cost and efficient transmission capable of changing to match the required conditions of output machine or actuator and the optimal operation of the input machine is difficult task. In addition, it is worth noting that a significant part of an energy conversion system cost is addressed to the control system, which is mostly determined by transmission. Thus, the transmission is a key factor for the power efficiency of most energy conversion systems.

Modern automobile engines must satisfy challenging and often conflicting requirements. Environmental concerns have motivated legislative action by governments around the world to reduce emissions of harmful gases, which require improved fuel economy, i.e. higher overall efficiency. On the other side, beside the efficiency, customers demand performance and comfort. All of these objectives must be delivered at low cost and high reliability. Manual transmissions can reach a relatively high efficiency - more than $96 \%$ [1], but they cannot offer neither the optimization of fuel consumption of the engine, nor the required driving comfort. Over the last two decades, significant scientific and professional effort has been directed towards developing vehicle transmissions that reduce the fuel consumption of automobile, as well as own energy losses. Those aims have been tried to achieve by continuously variable transmissions (CVTs) [2-8]. Although they have been successfully applied in some cars, the expected increase in fuel economy and acceleration performance has not been achieved [5]. Belt types CVTs achieved the efficiency of only $84.6 \%$ [1]. 
By authors' opinion, the control logic has not been the major cause of these shortcomings, as suggested by Srivastava and Haque [5], but primarily the nature of existing CVTs - the power losses and slippage caused by their friction element. In Toyota-Prius and other, following hybrid cars, a successful CVT transmissions are designed without a friction element, with differential gear train (DGT) enabling optimization of engine fuel consumption, but the price of motor-generators, control system and other electronics is high and overall efficiency is low due to double energy conversion losses in motor-generators. Automatic transmissions reach somewhat higher efficiency than CVTs (86 \%) [1], but still far from manual transmissions. They cannot enable the fuel consumption optimization and, together with control system, have high cost [9]. A significant step award is done with automated manual transmissions that have ordinary stepped gearbox and complex control systems (engine control and transmission control). As the gearbox is similar to that of pure manual one, they reach high efficiency similar or even higher than that of the pure manual transmission [1]. The speed change is carried out with speed control system (there is no clutch pedal) and minimum fuel consumption by engine speed control. In addition, they offer good driving comfort by achieving smooth gear shifting and best possible acceleration [1, 9, 10]. Although the expensive torque converter is replaced with gear shift controller, the cost of control system seems to remain too high and reliability questionable. Thus, it is still waiting for the transmission that will have driving characteristics and driver's comfort of a CVT, efficiency and cost close to manual transmission along with low emission of harmful gasses.

In the case of a wind turbine, despite the variable wind speed, the delivered power should have a constant frequency - whether or not it is grid connected. In the opposite case, many common appliances will not function properly [11]. Wind turbine should also be able to capture maximum energy from the wind. Having a fixed transmission ratio or direct drive, as frequently used so far, wind turbines have not been able to achieve this aims fairly, even with complex and high cost control system(s) [12] including frequency converter. The problems that appear are often solvable by mutually contradictory means. For example, extending variable speed range at constant tip speed ratio, the variable speed wind turbines have greater energy capture at higher aerodynamic efficiency, but the cost in power electronics is higher. By limiting the fatigue loads as one of the most critical issues of the wind turbine, i.e. limiting the amount and variability of torque, the optimum or constant power, or constant speed, is lost. The solution to achieve the aims and to avoid the problems of wind turbine design was naturally imposed: variable speed transmission with constant output speed.

Thus, designing the (variable speed ratio) transmission able to run a generator at constant speed and to enable the turbine rotor to capture maximum energy from the wind by the production cost as low as possible, has become an irresistible challenge. It also understands: low cost constant speed generator without frequency converter; reduced fatigue loads; increased transmission and overall power (energy) efficiency; reduced cost of control system; high operational reliability. It is a complex and difficult, but a reachable task. Respectable scientific effort has been made to approach this aim and various transmissions were offered. It will be mentioned some most successful, all applied in variable speed wind turbines and all hybrid, some kinds of CVT, thus with variable transmission ratio, enabling the constant output speed. So, Idan and Lior [13] proposed a hybrid variable speed transmission with two differential transmission stages in which the annulus gear speed of the second, three rotating shafts stage was controlled by three servo-motor generators (SMGs) to maintain the optimal rotor speed for a given wind speed, while the speed of the conventional asynchronous generator coupled with the sun gear was held constant. This design fulfils most of our requirements but has some shortcomings, including that the cost of the electronics is high because of the three SMGs used to balance the radial forces, that one fixed ratio DGT stage seems to be surplus, and that, when operated as a generator, the SMGs need a frequency converter to deliver power to the grid. Hicks and Cunliffe [14] presented a transmission consisting of a single DGT with its output shaft connected to the induction generator through a bevel gear drive, and the third shaft connected to a single SMG, which assisted by the control system enabled the output shaft to be maintained at a 
constant $( \pm 15 \%)$ speed. The shortcomings of this transmission are that the output speed is not quite constant, the bevel gear pair increases the cost of transmission and the power losses, and there are problems associated with the delivery of the SMG power to the grid. Zhao a Maißer [15] designed a power-split transmission with an electronically controlled DGT and two adjustment gear pairs, with one of the DGT shafts connected to the rotor shaft over the gear pair, another coupled to the generator and the third shaft connected to the SMG. The output generator speed was kept constant by controlling the speed of the servo motor. Apart from the questionable use of two additional gear drives, which increase machine costs and power losses, the same problems arise in delivering the SMG power as in previously described. In another scheme [16], a transmission has a single DGT, achieving a constant output speed by controlling the variable third shaft speed using a torque converter driven by the output shaft. This is a fine, innovative solution, but alongside the transmission, there was a conventional gearbox between the rotor and the DGT; when the torque converter and gearbox power losses and production costs are considered, the efficiency and production costs of this design may be considerable. Gomà Ayats et al. [17] proposed a CVT comprising a pair of DGTs with two shafts inter-connected over two variators, which actually function as gearboxes. The rest two shafts are the input and output. In this design, none transmission parameter prevails to much simpler, ordinary power-split CVT that consists of a single belt-type CVT and a single DGT [18, 19]: production cost, transmission ratio range and efficiency. Even, the continuous variation of output speed is not fully achieved. Recently, the hybrid transmission is proposed that avoids all the shortcomings of the variable speed wind turbines transmissions analysed above [20]. It enables constant speed of generator, maximum energy capture in the zone of low wind speeds with rotor blades in fixed geometry and constant power output, along with high transmission and overall efficiency. It consists of a single DGT and a simple control system with control motor fed directly from generator thus avoiding the problems of delivering the power of SMGs when they operate as generators. However, the built in power of electric machines is increased in this scheme.

Independently controllable transmission, appeared recently, which is able to run the output shaft at the controllable speed (including constant), independent of the input speed, thus applicable for automobile, wind turbine and all other transmissions with variable transmission ratio [21, 22]. It consists of two DGTs mutually connected with two ordinary gear trains (OGT): input one that splits the input power to DGTs and the output one, which receives the parts of the DGTs powers, sums them and sends to the output, so termed "free shaft". One of the rest of DGTs powers flows to the CMG shaft and the other to the real output shaft, while the speeds of their shafts are linearly dependent. That means that the output speed is controlled by the CMG speed, independently of the input speed. This transmission promises to solve most of the problems associated with variable-speed transmissions, including in automobiles and wind turbines. Moreover, it promises to achieve this with high efficiency (no friction element) and without control system. However, for a given input power, the output power of that transmission is huge due to huge control motor power - theoretically infinite, and practically hundred times greater than input power. In addition, it's "free shaft" runs at variable speed synchronous with an input speed. These shortcomings make that transmission practically unusable. Trying to design the same transmission without a free shaft, we found, as certainly, that, due to a complex kinematical and geometrical conditions that are required for DGTs and transmission as a whole, it is not feasible at all.

To obtain the feasible ICT, we sought to design the ICT with one more DGT added between two existing DGTs, which would connect the free shaft with two OGTs. We succeed to synthesize a series of ICT transmissions with three external shafts having mutually controllable speeds; at least one of them should be output. That process is presented in this paper.

\section{Synthesis of the novel series of ICT transmissions}


The transmission is based on the ability of DGTs to run two shafts at variable speed, while the speed of the third can be kept constant. Its basic configuration consists of three DGTs, A, B and C, having three rotating shafts mutually connected with two OGTs, D and E, Fig. 1 (a). The design pursuant to Fig. 1(b) should be applied when increase of input speeds of DGTs A and B and positive input speeds of all DGTs are needed. As common for DGTs with three rotating shafts, one of them should be hollow, with one of the rest shafts passing through it. In this transmission, the OGT D is connected with DGTs $A, B$ and $C$ with shafts $S_{A D}, S_{B D}$ and $S_{C D}$ passing through hollow shafts $S_{A E}, S_{B E}$ and $S_{C E}$ connecting the OGT E with DGTs. It is worth noting that OGT E can be placed also from the opposite (right) side of DGTs. The speeds of DGTs are related by the known Willis' formula [23, 24]:

$$
\begin{aligned}
& n_{1 \mathrm{~A}}-i_{0 \mathrm{~A}} n_{3 \mathrm{~A}}+\left(i_{0 \mathrm{~A}}-1\right) n_{\mathrm{CA}}=0 \\
& n_{1 \mathrm{~B}}-i_{0 \mathrm{~B}} n_{3 \mathrm{~B}}+\left(i_{0 \mathrm{~B}}-1\right) n_{\mathrm{CB}}=0 \\
& n_{1 \mathrm{C}}-i_{0 \mathrm{C}} n_{3 \mathrm{C}}+\left(i_{0 \mathrm{C}}-1\right) n_{\mathrm{CC}}=0
\end{aligned}
$$

where $n_{1 \mathrm{~A}}, n_{1 \mathrm{~B}}$ and $n_{1 \mathrm{C}}$ are the speeds of the central gears 1 of DGTs $\mathrm{A}, \mathrm{B}$ and C respectively; $n_{3 \mathrm{~A}}, n_{3 \mathrm{~B}}$ and $n_{3 \mathrm{C}}$ are the speeds of the central gears 3 of DGTs $\mathrm{A}, \mathrm{B}$ and $\mathrm{C}$ respectively; $n_{\mathrm{CA}}, n_{\mathrm{CB}}$ and $n_{\mathrm{CC}}$ are the speeds of the carriers of DGTs $\mathrm{A}, \mathrm{B}$ and $\mathrm{C}$, respectively; $i_{0 \mathrm{~A}}, i_{0 \mathrm{~B}}$ and $i_{0 \mathrm{C}}$ are the basic gear ratios (BGRs) of DGTs A, B and C, respectively.

By keeping in mind the ability of DGT mentioned above, and by prescribing in advance the constant speed ratios

$$
\alpha=\frac{n_{\mathrm{BD}}}{n_{\mathrm{AD}}}=\frac{n_{3}}{n_{2}}=\frac{z_{2}}{z_{3}}
$$

where $n_{\mathrm{BD}}$ and $n_{\mathrm{AD}}$ are the speeds of shafts $\mathrm{S}_{\mathrm{BD}}$ and $\mathrm{S}_{\mathrm{AD}}$ equal to the speeds $n_{2}$ and $n_{3}$ of gears 2 and 3 , respectively and $z_{2}$ and $z_{3}$ are the number of teeth of the gears 2 and 3, respectively;

$$
\beta=\frac{n_{\mathrm{B}}}{n_{\mathrm{A}}}
$$

where $n_{\mathrm{B}}$ and $n_{\mathrm{A}}$ are the speeds of external shafts $\mathrm{S}_{\mathrm{B}}$ and $\mathrm{S}_{\mathrm{A}}$, respectively;

$$
\gamma=\frac{n_{\mathrm{BE}}}{n_{\mathrm{AE}}}=\frac{n_{5}}{n_{4}}=\frac{z_{4}}{z_{5}}
$$

where $n_{\mathrm{BE}}$ and $n_{\mathrm{AE}}$ are the speeds of shafts $\mathrm{S}_{\mathrm{BE}}$ and $\mathrm{S}_{\mathrm{AE}}$ equal to the speeds $n_{5}$ and $n_{4}$ of gears 5 and 4 , respectively and $z_{4}$ and $z_{5}$ are the number of teeth of the gears 4 and 5, respectively;

$$
\delta=\frac{n_{\mathrm{CD}}}{n_{\mathrm{AD}}}=\frac{n_{1}}{n_{2}}=-\frac{z_{2}}{z_{1}}
$$

where $n_{\mathrm{CD}}$ is the speed of shaft $\mathrm{S}_{\mathrm{CD}}$ equal to the speed $n_{1}$ of gear 1, i.e. of the input shaft $S_{\mathrm{in}}$ and $z_{1}$ is the number of teeth of gear 1 ;

$$
\varphi=\frac{n_{\mathrm{CE}}}{n_{\mathrm{AE}}}=\frac{n_{6}}{n_{4}}=-\frac{z_{4}}{z_{6}},
$$


where $n_{\mathrm{CE}}$ is the speed of shaft $\mathrm{S}_{\mathrm{CE}}$ equal to the speed $n_{6}$ of gear 6 , and $z_{6}$ is the number of teeth of gear 6 ;

$$
\varepsilon=\frac{n_{\mathrm{C}}}{n_{\mathrm{A}}}
$$

where $n_{\mathrm{A}}, n_{\mathrm{B}}$ and $n_{\mathrm{C}}$ are the speeds of external shafts $\mathrm{S}_{\mathrm{A}}, \mathrm{S}_{\mathrm{B}}$ and $\mathrm{S}_{\mathrm{C}}$, respectively, it becomes clear that, for variable speed of the input shaft $S_{\text {in }}$, all the shafts of the transmission will rotate at variable speed, except the shafts $S_{A}, S_{B}$ and $S_{C}$ whose speeds are mutually linearly dependent, and two of them are controlled by the speed of the third, connected to CMG. Thus, they are controllable - independent of the transmission input shaft speed.

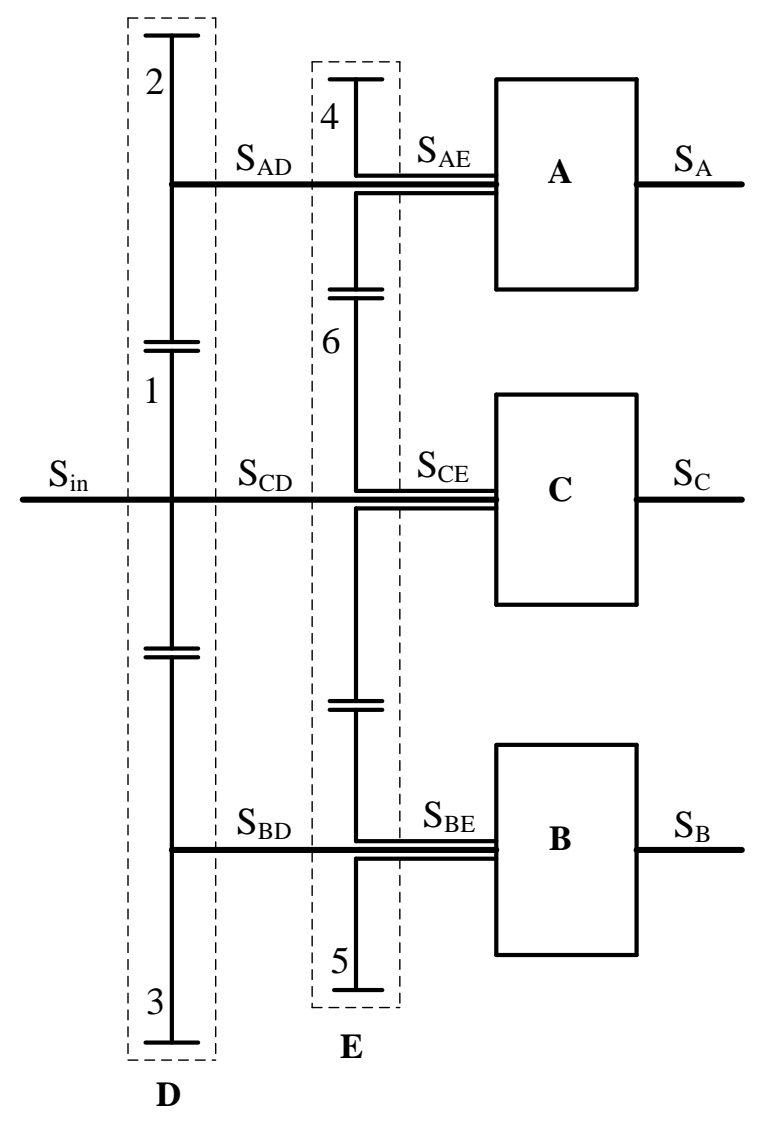

a)

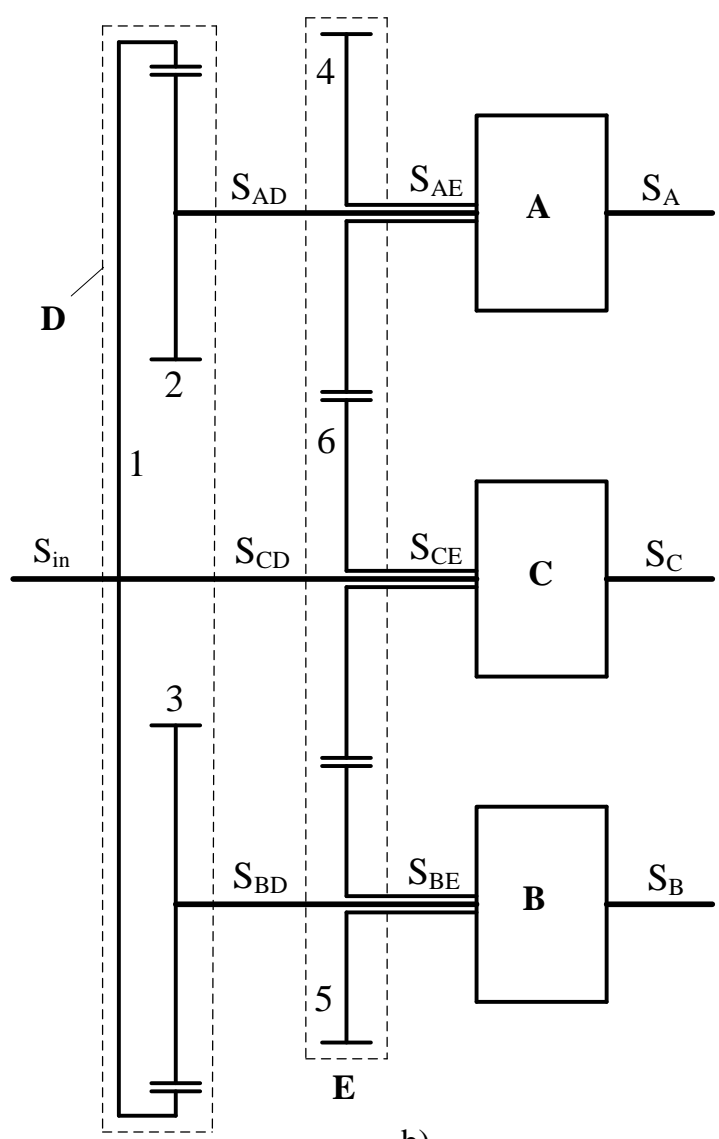

b)

Figure 1. Schematic of the basic configurations of the transmission a) input gear 1 with external toothing b) input gear 1 with internal toothing

The fundamental challenge of designing the transmission is to determine such the BGRs of DGTs A, $\mathrm{B}$, and $\mathrm{C}$, which will, for a certain addressing (i.e. connecting) the DGTs shafts to OGTs shafts, result in the feasible ICT able to run all the external shafts, except the input one, at controllable speeds. To achieve this goal, i.e. to realize the ICT with required power flows of external shafts, it is necessary to:

- go by the rule of DGTs shaft powers: they are positive (input) for the same signs of the speed and torque, and negative (output) in the opposite case

- choose the placement of DGTs shafts (addressing to shafts of OGTs)

- distribute the speed and torque signs to obtain the required power flows

- check whether at least one of DGTs shafts has a torque sign different of two rest 
- check whether at least one of DGTs shafts has a power sign different of two rest

- $\quad$ derive the formulas for $i_{0 \mathrm{~A}}$ and $i_{0 \mathrm{~B}}$ as functions of speed ratios $\alpha, \beta$ and $\gamma$.

- from torque signs of DGT $\mathrm{B}$, determine the range of $i_{0 \mathrm{~B}}$. It enables to

- determine the ranges of speed ratios $\alpha, \beta$ and $\gamma$

- check whether those ranges result in the range of $i_{0 \mathrm{~A}}$ that corresponds to torque signs of DGT A

- check whether the speeds of summation shafts of DGTs A and B lie between the speeds of the central gear shafts $[23,24]$, meaning that at least one of the central gear shafts must have the same speed sign as the summation shaft

- check for both A and B DGTs whether the power flow conditions are satisfied that result in the speed ratio ranges condition of central gears shafts

- check whether those ranges of speed ratios are convenient for the planned transmission

- choose the numerical values of speed ratios $\alpha, \beta$ and $\gamma$. It is worth noting that by adding one idle gear between gear 1 and gear 2 or 3 and between gear 6 and gear 4 or 5 , the signs of speed ratios $\alpha$ and $\gamma$ can be changed

- calculate the number of teeth of gears 2,3,4 and 5 and difference $z_{1}-z_{6}$ from the geometry conditions (equality of centre distances of OGTs D and E assuming same modules)

- derive the compatibility function for DGT C in dependence of speed ratios $\alpha, \beta$ and $\gamma$

- choose shaft placement and sign distribution for DGT C in accordance with the compatibility function and speed ratios $\alpha, \beta$ and $\gamma$, taking into account the required power flows, the rules of torque and power signs and the speed sign of summation shaft

- derive $i_{0 \mathrm{C}}$ as function of speed ratios $\delta, \varepsilon$ and $\varphi$

- check the power flow condition of DGT C

- choose the numerical value of $i_{0 \mathrm{C}}$ in accordance with torque signs of the shafts and find the compatibility point at the compatibility function

- calculate the ratio $z_{1} / z_{6}$ and consequently the number of teeth $z_{1}$ and $z_{6}$. When $z_{1} / z_{6}$ is obtained less than unity and $z_{1}-z_{6}$ is positive, or opposite, or if some gear ratio is not within allowed limits, some other value of BGR should be chosen.

- calculate the numerical values of speed $\operatorname{ratios} \delta, \varepsilon$ and $\varphi$

- check whether $i_{0 \mathrm{C}}$ calculated by the derived formula is equal to that anticipated. If so

- calculate the numerical values of $i_{0 \mathrm{~A}}$ and $i_{0 \mathrm{~B}}$ and finish the design of DGTs by determining the number of teeth of central gears and planets, taking into account the mating conditions.

If the final result is not satisfying in any way, e.g. if the range of transmission ratio does not comprehend the required one, some other placement of shafts of DGTs A and B should be chosen that should result in other ranges of speed ratios $\alpha, \beta$ and $\gamma$, and design procedure repeated.

To conjure up the procedure of the design, the ICT synthesis is going to be presented in a separate chapter.

\section{Example of design}

For a vehicle transmission, it is supposed that distribution of the speed, torque and power signs of DGTs A and B, as presented in Table 1, would be convenient.

The basic gear ratios of DGTs A and B are determined by expressing some of the speed ratios $\alpha, \beta$ or $\gamma$ as a function of shaft speed ratios of each DGT. For this purpose, the speeds $n_{\mathrm{AE}}$ and $n_{\mathrm{BE}}$ of the shafts $\mathrm{S}_{\mathrm{AE}}$ and $\mathrm{S}_{\mathrm{BE}}$ should be derived from (1) and (2), in accordance with Table 1:

$$
n_{\mathrm{AE}}=\frac{n_{\mathrm{AD}}-i_{0 \mathrm{~A}} n_{\mathrm{A}}}{1-i_{0 \mathrm{~A}}}
$$




$$
n_{\mathrm{BE}}=\frac{n_{\mathrm{BD}}-i_{0 \mathrm{~B}} n_{\mathrm{B}}}{1-i_{0 \mathrm{~B}}}
$$

Dividing (11) by (10), gives the following:

$$
\gamma=\frac{1-i_{0 \mathrm{~A}}}{1-i_{0 \mathrm{~B}}} \frac{\alpha-\beta i_{0 \mathrm{~B}} n_{\mathrm{A}} / n_{\mathrm{AD}}}{1-i_{0 \mathrm{~A}} n_{\mathrm{A}} / n_{\mathrm{AD}}} .
$$

The basic gear ratio of DGT, defined by two speed ratios, does not depend on a single speed ratio, i.e. it remains constant for any change of a single speed ratio, while the other speed ratio vary in accordance with Willis' equation. This is valid for any state of speeds, including at the coupling point where all the speeds are the same, i.e. the speed ratios are unity. Therefore, when the single ratio of DGT shaft speeds appears as a single variable in an equation, the equation is also valid for speed ratio of unity. When the rule applies to a transmission of interest, Eq. (12) converts to

$$
\gamma=\frac{\alpha-\beta i_{0 \mathrm{~B}}}{1-i_{0 \mathrm{~B}}}
$$

where from the needed value of DGT B basic gear ratio is derived as follows:

$$
i_{0 \mathrm{~B}}=\frac{\alpha-\gamma}{\beta-\gamma} .
$$

Table 1. Distribution of speed, torque and power signs of DGTs A and B

\begin{tabular}{|l|l|l|l|l|l|}
\hline \multicolumn{3}{|c|}{ Differential gear train A } & \multicolumn{3}{c|}{ Differential gear train B } \\
\hline $\begin{array}{l}\text { Central gear 1 } \\
\text { shaft position }\end{array}$ & $\begin{array}{l}\text { Central gear 3 } \\
\text { shaft position }\end{array}$ & $\begin{array}{l}\text { Carrier shaft } \\
\text { position }\end{array}$ & $\begin{array}{l}\text { Central gear 1 } \\
\text { shaft position }\end{array}$ & $\begin{array}{l}\text { Central gear 3 } \\
\text { shaft position }\end{array}$ & $\begin{array}{l}\text { Carrier shaft } \\
\text { position }\end{array}$ \\
\hline Shaft $\mathbf{S}_{\mathrm{AD}}$ & Shaft $\mathrm{S}_{\mathrm{A}}$ & Shaft $\mathrm{S}_{\mathrm{AE}}$ & Shaft $\mathbf{S}_{\mathrm{BD}}$ & Shaft $\mathrm{S}_{\mathrm{B}}$ & Shaft $\mathbf{S}_{\mathrm{BE}}$ \\
\hline$n_{\mathrm{AD}}<0$ & $n_{\mathrm{A}}<0$ & $n_{\mathrm{AE}}<0$ & $n_{\mathrm{BD}}<0$ & $n_{\mathrm{B}}<0$ & $n_{\mathrm{BE}}<0$ \\
\hline$T_{\mathrm{AD}}<0$ & $T_{\mathrm{A}}>0$ & $T_{\mathrm{AE}}>0$ & $T_{\mathrm{BD}}<0$ & $T_{\mathrm{B}}>0$ & $T_{\mathrm{BE}}>0$ \\
\hline$P_{\mathrm{AD}}>0$ & $P_{\mathrm{A}}<0$ & $P_{\mathrm{AE}}<0$ & $P_{\mathrm{BD}}>0$ & $P_{\mathrm{B}}<0$ & $P_{\mathrm{BE}}<0$ \\
\hline
\end{tabular}

* Summation shaft are bolded

In a similar way, after dividing Eq. (11) by Eq. (10), setting the speed ratio $n_{\mathrm{B}} / n_{\mathrm{BD}}$ to unity, gives the following equation for the basic gear ratio $i_{0 \mathrm{~A}}$ :

$$
i_{0 \mathrm{~A}}=\frac{\beta}{\alpha} \frac{\alpha-\gamma}{\beta-\gamma} .
$$

The transmission is designed under presumption of positive basic gear ratios for all DGTs. Thus, it is necessary to check whether it is possible to realize for the established ranges of the speed ratios $\alpha, \beta$ and $\gamma$ and for expressions derived. Namely, the condition $i_{0 \mathrm{~B}}>0$ is fulfilled if only $\alpha>\gamma$ and $\beta>\gamma$ or $\alpha<\gamma$ and $\beta<\gamma$. Whereas, from torque equilibrium equation [23, 24] and for neglected friction losses in DGT B, the torque ratio of the carrier and central gear 1 shafts should be 


$$
\frac{T_{\mathrm{BE}}}{T_{\mathrm{BD}}}=i_{0 \mathrm{~B}}-1<0,
$$

see Table 1, it follows $i_{0 \mathrm{~B}}<1$. Now, it is easy to observe that for $\alpha>\gamma<\beta$ it follows $\gamma<\alpha<\beta$, and for $\alpha<\gamma>\beta$ it follows $\beta<\alpha<\gamma$. The former one is chosen, thus:

$$
\gamma<\alpha<\beta \text {. }
$$

The torque ratio of the carrier and central gear 1 shafts of DGT A should also be $i_{0 \mathrm{~A}}<1$, which condition is fulfilled for both ranges of speed ratios $\alpha$ and $\beta$, as well.

The speed ratios of a particular DGT should also fulfil the power flows condition [24], which is derived from condition that a ratio of two output shaft powers should be positive. For power-split DGT A having a central gear 1 as power summation shaft, in accordance with 1 , the following condition should be fulfilled:

$$
\frac{n_{\mathrm{AD}}}{n_{\mathrm{A}}}=i_{0 \mathrm{~A}}+\left(1-i_{0 \mathrm{~A}}\right) \frac{n_{\mathrm{AE}}}{n_{\mathrm{A}}}>i_{0 \mathrm{~A}},
$$

which reduces to the condition

$$
\left(1-i_{0 \mathrm{~A}}\right) \frac{n_{\mathrm{AE}}}{n_{\mathrm{A}}}>0,
$$

which is always fulfilled, see Table 1. The power flow condition for DGT B fulfils the similar condition:

$$
\left(1-i_{0 \mathrm{~B}}\right) \frac{n_{\mathrm{BE}}}{n_{\mathrm{B}}}>0 .
$$

Thus, the feasibility of the link A-B is proved.

Differential gear train $\mathrm{C}$ should be compatible with both DGTs A and B. Thus, its BGR should be same for both kinematic links DGT A - DGT C and DGT B - DGT C. From DGT A - DGT C link, in the same way as for link DGT A - DGT B, the BGR of DGT C is obtained for the shaft placement and signs distribution presented in Table 2:

$$
i_{0 \mathrm{C}}=\frac{\delta-\varphi}{\varepsilon-\varphi}
$$

The same value of $i_{0 \mathrm{C}}$ should be obtained from the link DGT B - DGT C. Therefore, the corresponding speed ratios should be defined:

$$
\begin{gathered}
\lambda=\frac{n_{\mathrm{CD}}}{n_{\mathrm{BD}}}=\frac{n_{1}}{n_{3}}=-\frac{z_{3}}{z_{1}}=\frac{\delta}{\alpha} \\
\rho=\frac{n_{\mathrm{CE}}}{n_{\mathrm{BE}}}=\frac{n_{6}}{n_{5}}=-\frac{z_{5}}{z_{6}}=\frac{\varphi}{\gamma}
\end{gathered}
$$




$$
\mu=\frac{n_{C}}{n_{B}}=\frac{\varepsilon}{\beta} .
$$

The formula for BGR of DGT C is now derived:

$$
i_{0 \mathrm{C}}=\frac{\lambda-\rho}{\mu-\rho} .
$$

By equalizing Eqs. (21) and (25), the compatibility function is derived that should be fulfilled to enable the DGT C to be compatible with DGTs A and B:

$$
y_{\mathrm{com}}=\frac{\beta(\gamma-\alpha) x}{\gamma(\beta-\alpha) x-\alpha(\beta-\gamma)}
$$

where $y_{\text {com }}=\varepsilon / \varphi$ and $x=\delta / \varphi$.

Table 2. Distribution of speed, torque and power signs of DGT C

\begin{tabular}{|l|l|l|}
\hline $\begin{array}{l}\text { Central gear } \\
1 \text { shaft } \\
\text { position }\end{array}$ & $\begin{array}{l}\text { Central gear } \\
3 \text { shaft } \\
\text { position }\end{array}$ & $\begin{array}{l}\text { Carrier shaft } \\
\text { position }\end{array}$ \\
\hline Shaft $\mathbf{S}_{\mathrm{CD}}$ & Shaft $\mathrm{S}_{\mathrm{C}}$ & Shaft $\mathrm{S}_{\mathrm{CE}}$ \\
\hline$n_{\mathrm{CD}}>0$ & $n_{\mathrm{C}}>0$ & $n_{\mathrm{CE}}>0$ \\
\hline$T_{\mathrm{CD}}<0$ & $T_{\mathrm{C}}>0$ & $T_{\mathrm{CE}}>0$ \\
\hline$P_{\mathrm{CD}}<0$ & $P_{\mathrm{C}}>0$ & $P_{\mathrm{CE}}>0$ \\
\hline
\end{tabular}

It is interesting and quite understandable that the function remains the same for any placement of the shafts of DGT C and for any distribution of speed, torque and power flow signs. There are three possible graphs of compatibility function depending only on the order by attitudes of the ranges of speed ratios $\alpha, \beta$ and $\gamma$, Fig. 3, each with one horizontal and one vertical asymptote. It is interesting that the function always passes through the point $\left(x_{1}=1 ; y_{1}=1\right)$ which is the coupling point of DGT $\mathrm{C}$ and entire transmission thus cannot be the acceptable solution. The BGR for a certain placement of the shafts of DGT C can also be expressed in the form of function $y_{\mathrm{C}}=y_{\mathrm{C}}(x)$. It is a straight line passing also through the coupling point. For obtained $i_{0 \mathrm{C}}$, Eq. $(21)$, its function in $(x, y)$ diagram is derived as follows:

$$
y_{\mathrm{C}}=\frac{x}{i_{0 \mathrm{C}}}-\frac{1-i_{0 \mathrm{C}}}{i_{0 \mathrm{C}}}
$$

This straight line intersects the compatibility function in two points, Fig. 2: the coupling point, $\left(x_{1}\right.$, $\left.y_{1}\right)$, and the other, $\left(x_{2}, y_{2}\right)$, the required one, that should be obtained by solving the system of two equations, (26) and (27).

Because the compatibility function is determined by known ranges of possible values of speed ratios $\alpha, \beta$ and $\gamma$, it is possible, by choosing the signs of DGT C shafts speeds, taking into account the required power flows, to aim at one of the solution points $\left(x_{2}, y_{2}\right)$ in advance, Fig. 2 . The formulas for $i_{0 \mathrm{C}}$ and its function $y_{\mathrm{C}}$, as well as the signs of slopes $a$ and $y$-intercepts $b$ of the $y_{\mathrm{C}}$ function for all 
possible placement of shafts, are presented in Table 3, to make this procedure easier for designer. It is to be emphasized that for any combination of signs of speed ratios $\alpha, \beta$ and $\gamma$, one of drawings in Fig. 2 is applicable.

a)

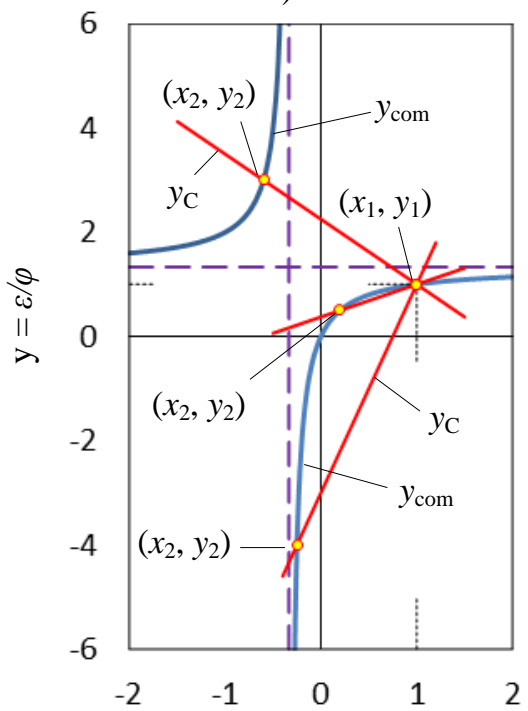

b)

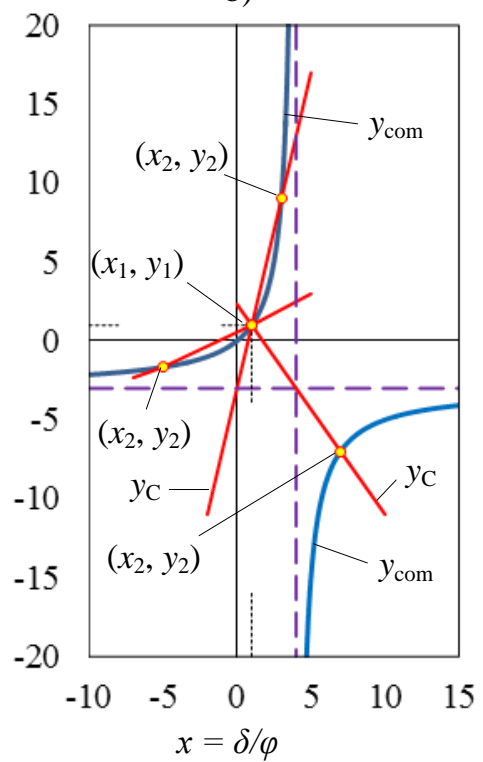

c)

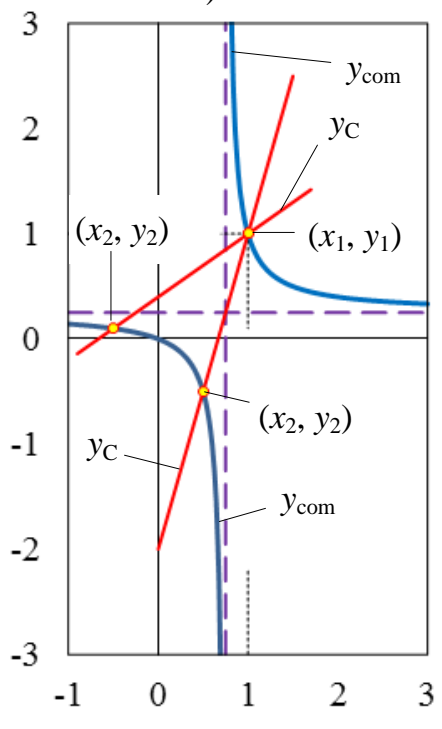

Figure 2. Compatibility functions and possible solutions for $\delta / \varphi$ and $\varepsilon / \varphi$ for positive values of speed ratios $\alpha, \beta$ and $\gamma$

a) for $\alpha<\beta<\gamma$ and $\gamma<\beta<\alpha$ b) for $\gamma<\alpha<\beta$ and $\beta<\alpha<\gamma$ c) for $\beta<\gamma<\alpha$ and $\alpha<\gamma<\beta$

Table 3. Formulas for $i_{0}$ and their functions $y_{\mathrm{c}}$

\begin{tabular}{|c|c|c|c|c|c|c|c|c|}
\hline & $\begin{array}{l}\text { Central } \\
\text { gear } 1\end{array}$ & $\begin{array}{c}\text { Central } \\
\text { gear } 3\end{array}$ & Carrier & $i_{0 \mathrm{C}}$ & $y_{\mathrm{C}}$ & $0<i_{0 \mathrm{C}} \leq 1$ & $i_{0 \mathrm{C}}>1$ & $i_{0 \mathrm{C}}<0$ \\
\hline \multirow{6}{*}{ 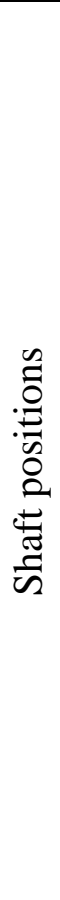 } & $\mathrm{S}_{\mathrm{CD}}$ & $\mathrm{S}_{\mathrm{CE}}$ & $\mathrm{S}_{\mathrm{C}}$ & $\frac{\delta-\varepsilon}{\varphi-\varepsilon}$ & $\frac{x}{1-i_{0 \mathrm{C}}}+\frac{i_{0 \mathrm{C}}}{i_{0 \mathrm{C}}-1}$ & $a>0 \quad b<0$ & $a<0 \quad b>0$ & $a>0 \quad b>0$ \\
\hline & $\mathrm{S}_{\mathrm{CE}}$ & $\mathrm{S}_{\mathrm{CA}}$ & $\mathrm{S}_{\mathrm{C}}$ & $\frac{\varphi-\varepsilon}{\delta-\varepsilon}$ & $\frac{i_{0 \mathrm{C}} x}{i_{0 \mathrm{C}}-1}-\frac{1}{i_{0 \mathrm{C}}-1}$ & $a<0 \quad b>0$ & $a>0 \quad b<0$ & $a>0 \quad b>0$ \\
\hline & $\mathrm{S}_{\mathrm{CD}}$ & $\mathrm{S}_{\mathrm{C}}$ & $\mathrm{S}_{\mathrm{CE}}$ & $\frac{\delta-\varphi}{\varepsilon-\varphi}$ & $\frac{x}{i_{0 \mathrm{C}}}-\frac{1-i_{0 \mathrm{C}}}{i_{0 \mathrm{C}}}$ & $a>0 \quad b<0$ & $a>0 \quad b>0$ & $a<0 \quad b>0$ \\
\hline & $\mathrm{S}_{\mathrm{C}}$ & $\mathrm{S}_{\mathrm{CD}}$ & $\mathrm{S}_{\mathrm{CE}}$ & $\frac{\varepsilon-\varphi}{\delta-\varphi}$ & $i_{\mathrm{OC}} x+1-i_{0 \mathrm{C}}$ & $a>0 \quad b>0$ & $a>0 \quad b<0$ & $a<0 \quad b>0$ \\
\hline & $\mathrm{S}_{\mathrm{CE}}$ & $\mathrm{S}_{\mathrm{C}}$ & $\mathrm{S}_{\mathrm{CD}}$ & $\frac{\varphi-\delta}{\varepsilon-\delta}$ & $\frac{i_{0 \mathrm{C}}-1}{i_{0 \mathrm{C}}} x+\frac{1}{i_{0 \mathrm{C}}}$ & $a<0 \quad b>0$ & $a>0 \quad b>0$ & $a>0 \quad b<0$ \\
\hline & $\mathrm{S}_{\mathrm{C}}$ & $\mathrm{S}_{\mathrm{CE}}$ & $\mathrm{S}_{\mathrm{CD}}$ & $\frac{\varepsilon-\delta}{\varphi-\delta}$ & $\left(1-i_{0 \mathrm{C}}\right) x+i_{0 \mathrm{C}}$ & $a>0 \quad b>0$ & $a<0 \quad b>0$ & $a>0 \quad b<0$ \\
\hline
\end{tabular}

The results of calculation are presented in Table 4 for the chosen values of speed ratios $\alpha, \beta$ and $\gamma$, and BGR of DGT C, $i_{0 C}=1 / 3$. The number of teeth of DGTs, calculated in accordance with geometrical and kinematic conditions, including mating conditions of DGTs, is presented in a separate Table 5. 
The number of planets for DGT A should be three or five, for DGT B three or four, and for DGT C three, four or five. Thus, gear modules of DGTs will be significantly lower than that of OGTs, so DGTs can be properly accommodated.

Table 4. Numerical results of design example of the transmission

\begin{tabular}{|l|l|l|l||}
\hline Designation and symbol & $\begin{array}{l}\text { Used equation, or } \\
\text { equation }\end{array}$ & Result & Note \\
\hline Speed ratios: $\alpha, \beta$, and $\gamma$ & & $\begin{array}{l}\gamma=2 / 3 ; \alpha=3 / 4 ; \\
\beta=4 / 5\end{array}$ & Chosen \\
\hline Gear ratio, $z_{5} / z_{3}$ & $\frac{z_{5}}{z_{3}}=\frac{1-\alpha}{1-\gamma}$ & $3 / 4$ & $\begin{array}{l}\text { From equality of } \\
\text { centre distances }\end{array}$ \\
\hline Number of teeth & $(4)$ and $(5)$ & $\begin{array}{l}z_{2}=72 ; z_{3}=96 \\
z_{4}=48, \quad z_{5}=72\end{array}$ & $\begin{array}{l}\text { One of these should be } \\
\text { chosen }\end{array}$ \\
\hline Difference, $\left(z_{6}-z_{1}\right)$ & $\frac{z_{2}+z_{3}}{2}-\frac{z_{4}+z_{5}}{2}$ & 24 & $\begin{array}{l}\text { Also equal to } \\
\left(z_{2}-z_{4}\right)\end{array}$ \\
\hline Compatibility function, $y_{\mathrm{com}}$ & $(26)$ & $y_{\mathrm{com}}=\frac{2 x}{3-x}$ & See Fig. 3 \\
\hline BGR function, $y_{\mathrm{C}}$ & $(27)$ & $y_{\mathrm{C}}=3 x-2$ & For $i_{0 \mathrm{C}}=1 / 3$ \\
\hline Compatible solution & $(26)$ and $(27)$ & $x=2 ; y=4$ & \\
\hline Ratio $z_{6} / z_{1}$ & $x=\delta / \varphi$ & $4 / 3$ & $z_{6}=96 ; z_{1}=72$ \\
\hline Number of teeth: $z_{6}$ and $z_{1}$ & & $\begin{array}{l}\varphi=-1 / 2 ; \delta=-1 ; \\
\varepsilon=-2\end{array}$ & \\
\hline Speed ratios: $\delta, \varphi, \varepsilon$ & $(7),(8)$ and $(9)$ & $i_{0 \mathrm{C}}=1 / 3$ & $i_{0 \mathrm{~B}}=5 / 8$ \\
\hline Basic gear ratio, $i_{0 \mathrm{C}}$ & $(21)$ & $i_{0 \mathrm{~A}}=2 / 3$ & \\
\hline Basic gear ratio, $i_{0 \mathrm{~B}}$ & $(14)$ & $(15)$ & \\
\hline Basic gear ratio, $i_{0 \mathrm{~A}}$ & & & \\
\hline \hline
\end{tabular}

The ICT is obtained with two output shafts whose speeds are controlled by the shaft $\mathrm{S}_{\mathrm{C}}$ connected to control motor, Fig. 3 where the power flow directions in that and following figures are marked with arrows. The output shaft having greater power delivers the power towards wheels, e.g. $S_{A}$, that rotate with required speed controlled by control motor, while the other, $\mathrm{S}_{\mathrm{B}}$, via generator and AC/DC converter, fills the battery. The control motor is fed by the battery via inverter, as well as auxiliary devices (engine starter, air conditioning, pumps etc.). Because the power ratio of output shafts is given in advance, this power can be set as high as needed for drive the wheels. Thus, by adding few clutches, brakes, electronic components and corresponding control system, the transmission can be used for hybrid vehicles.

Table 5. Number of teeth of DGTs

\begin{tabular}{|l|l|l|l|l|l|l|l|l|l|l|l|l|}
\hline $\begin{array}{l}\text { Gear } \\
\text { mark }\end{array}$ & $1 \mathrm{~A}$ & $2 \mathrm{~A}$ & $2^{\prime} \mathrm{A}$ & $3 \mathrm{~A}$ & $1 \mathrm{~B}$ & $2 \mathrm{~B}$ & $2^{\prime} \mathrm{B}$ & $3 \mathrm{~B}$ & $1 \mathrm{C}$ & $2 \mathrm{C}$ & $2^{\prime} \mathrm{C}$ & $3 \mathrm{C}$ \\
\hline
\end{tabular}




\begin{tabular}{|l|l|l|l|l|l|l|l|l|l|l|l|l|}
\hline $\begin{array}{l}\text { Number } \\
\text { of teeth }\end{array}$ & 54 & 36 & 45 & 45 & 32 & 28 & 35 & 25 & 36 & 24 & 40 & 20 \\
\hline
\end{tabular}
* gear marks in accordance with Figure. 3

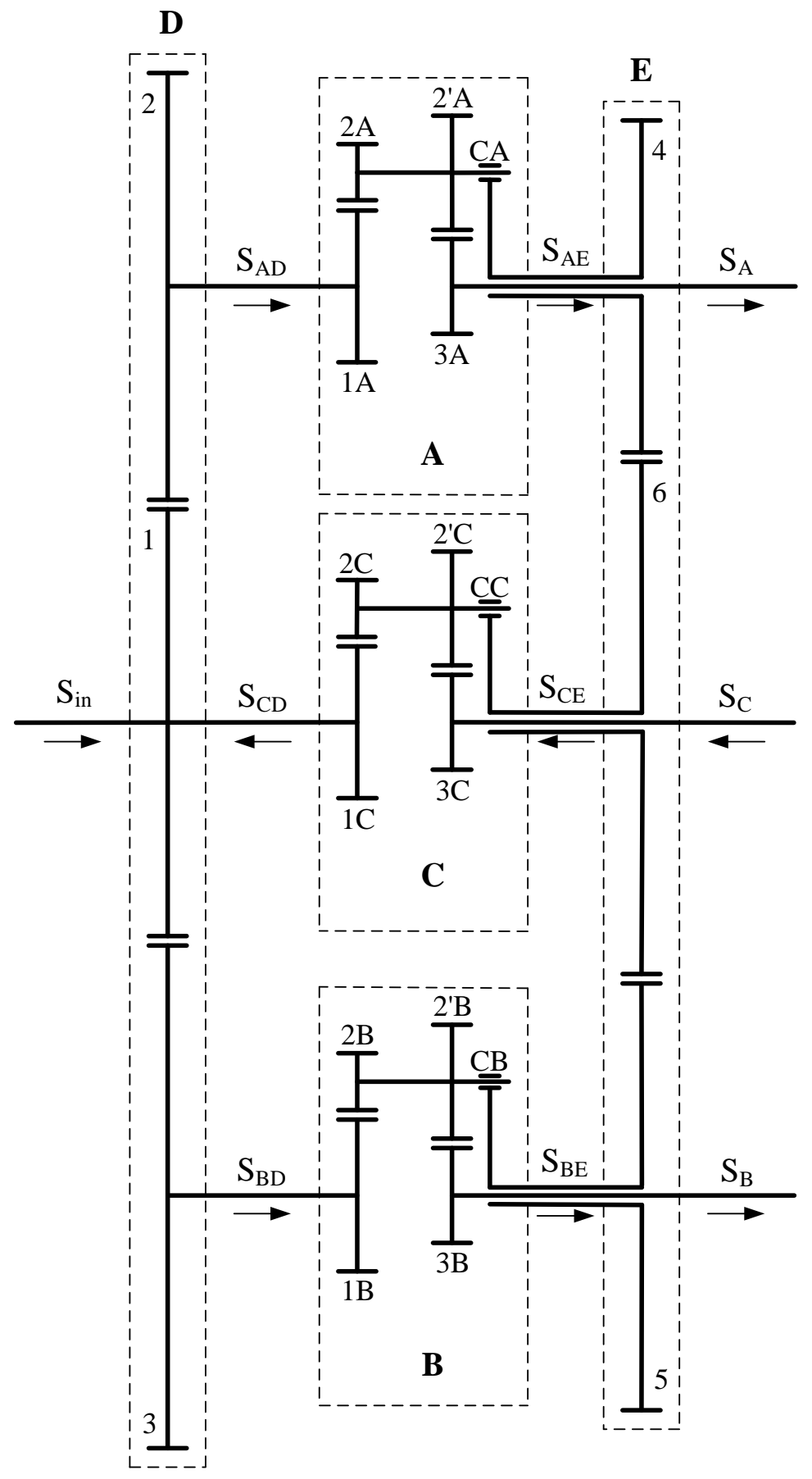

Figure 3. Schematic of the example transmission

It is notable that the power of $\mathrm{S}_{\mathrm{CD}}$ shaft is the output shaft of DGT C and input shaft of OGT D. Thus it circulates inside the transmission in two closed circles: DGT C - OGT D -DGT A - OGT E - DGT C and DGT C - OGT D -DGT B - OGT E - DGT C and never reaches an output shaft.

It is also possible to split the power of the output shaft having power greater than $\mathrm{S}_{\mathrm{C}}$ shaft into two parts by means of an additional, simple gear drive F: the power flowing to input shaft of DGT C, and the rest flowing to $C M G\left(S_{C M G}\right.$ shaft $)$ that controls the speed of the real output shaft $S_{\mathrm{A}}$ and fills the battery, Fig. 4. It results in the following benefits: i) reduced cost; the control motor of high power is 
replaced with generator of low power, power inverter is avoided, battery capacity and size are reduced, and ii) efficiency of transmission and entire power train is improved. The power of $S_{C}$ shaft also circulates inside the transmission now, in the circle DGT C - OGT E - DGT B - OGT F - DGT C.

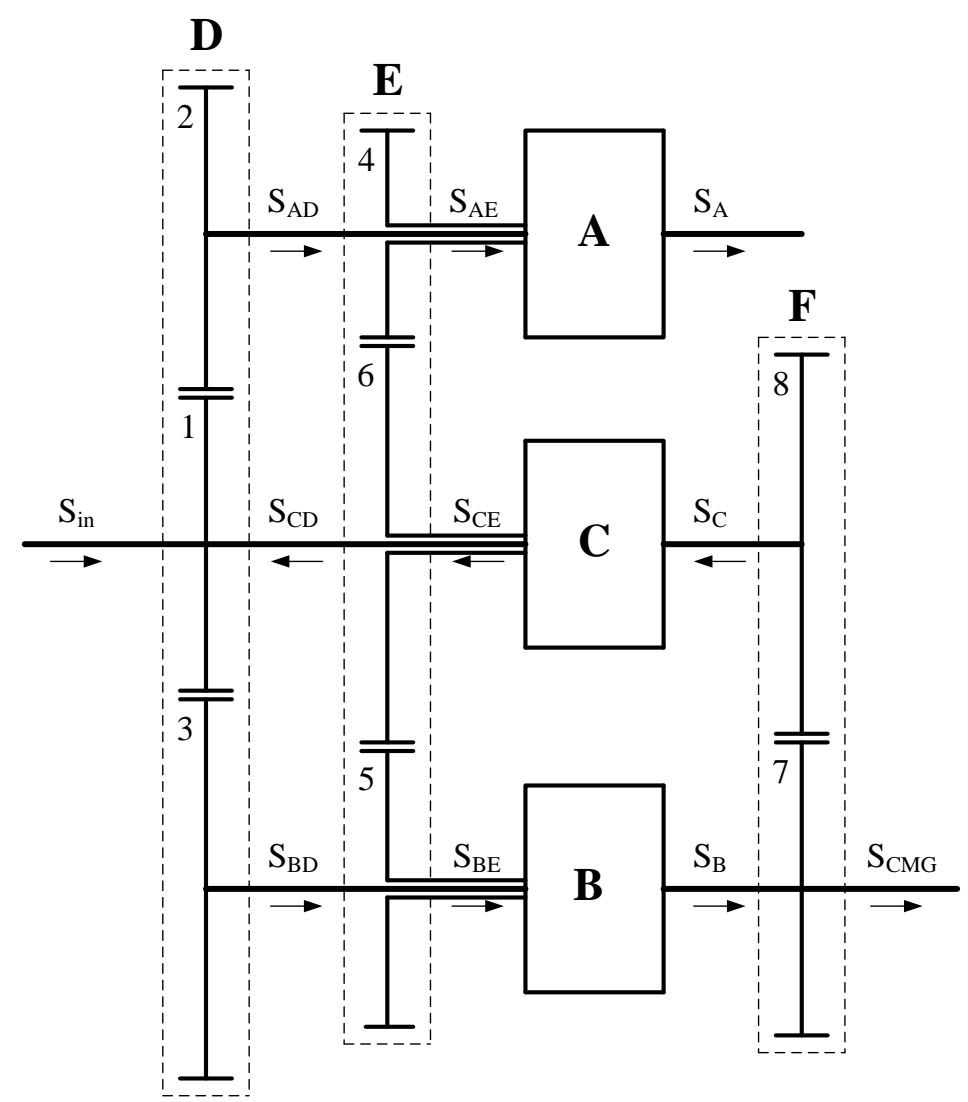

Figure 4. Version of the transmission with two output shafts

Because the speeds of input and output shafts are mutually independent, the presented transmissions have superior feature: ability to enable both the driving and driven machine to operate at optimal speeds by means of simple control system. As we are limited to a vehicle transmission in this example, where the speed of output shaft is determined by driver's will, it remains only the optimization of the driving machine shaft speed. For this purpose, the simple control system is required and the transmission pursuant to Fig. 4 is adapted by mating a single gear 9 with gear 4 or 5 of OGT D, Fig. 5. Its shaft, $\mathrm{S}_{\mathrm{CM}}$, is connected to control motor that forces the prime mover shaft to operate at optimal speed for any speed of output shaft. A microprocessor receives the signals of output shaft speed and torque; calculates the required power of the input machine; calculates the intersection point of input power curve and optimal operating line (in the case of ICE) in speed-torque diagram; calculates the required speed of control motor shaft and sends it to the regulatory member of control motor, forcing it to run at the speed that results in optimal speed of prime mover. The control motor is fed with CMG power, directly, via frequency converter or indirectly, via converter, battery and inverter.

This, final version of the transmission is animated for a vehicle speeds according to UN ECE testing procedure, for a wheels dynamic radius of $0.277 \mathrm{~m}$, for differential transmission ratio of 2.0 and for randomly chosen input speed variation within the required range, Fig. 6 . The time-speed history of the controllable speeds of shafts $S_{A}, S_{B}$ and $S_{C}$ is obtained, Fig. 7. It is obvious the independence of controllable speeds from the input speed. The same diagram, for minimum fuel consumption, is likely to be presented in a future work as result of dynamic analysis. 


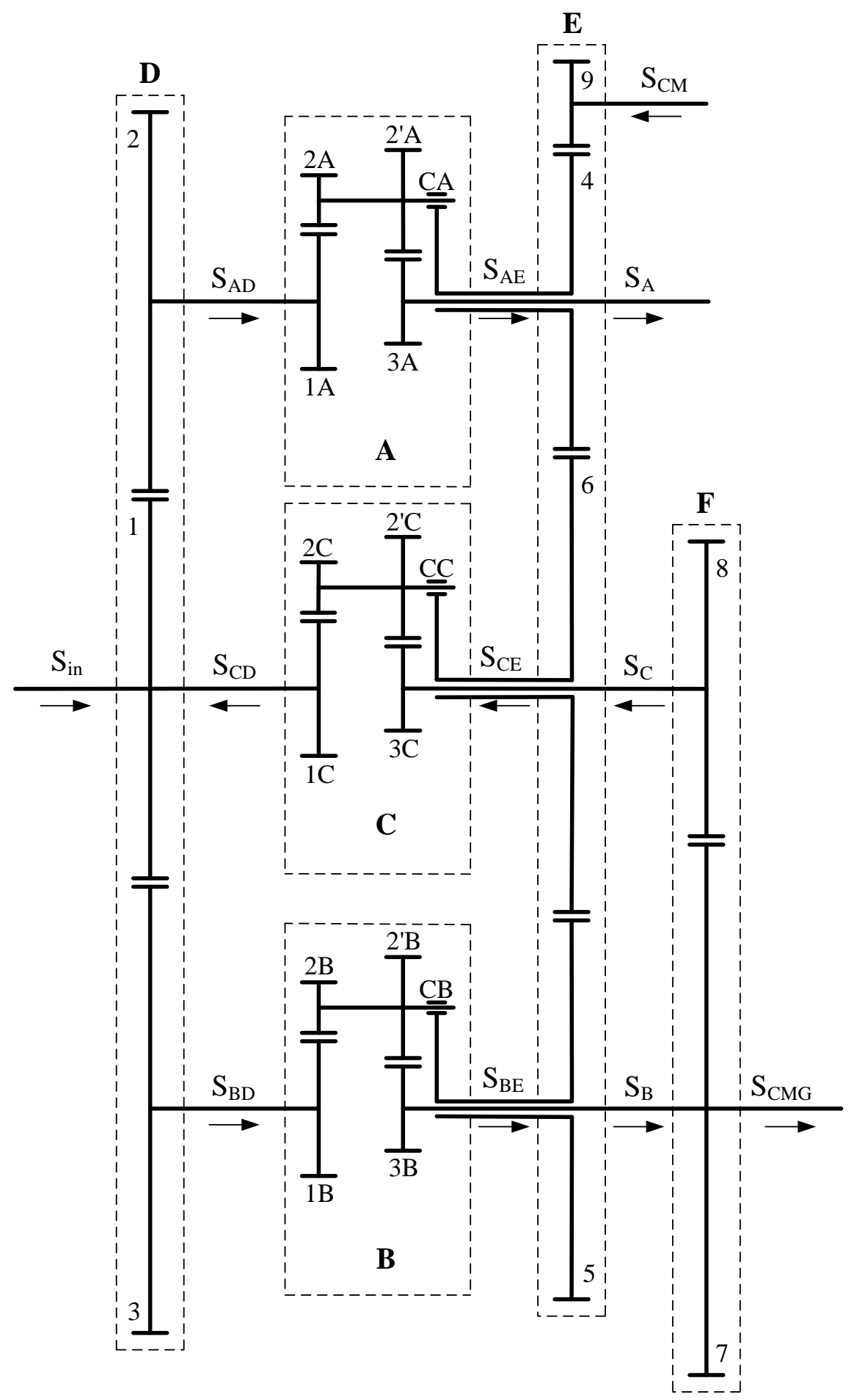

Figure 5. Schematic of the example transmission addressed to a vehicle

In other than vehicle transmissions, the cost of CMG can be avoided by adding the speed controller to output machine (e.g. to electric generator) and by connecting shafts $S_{A}$ and $S_{C M G}$ into the single output shaft by means of an additional OGT. In such a way, the transmission can have in total two external shafts: input of arbitrary speed and output of controlled speed. However, the optimization is not attained in such a case.

\section{Concluding remarks}


A novel type of ICT is proposed with basic design having four external shafts among which only the speed of input shaft is arbitrary, while the others are mutually controllable. It is a CVT that consists of three DGTs and at least two OGTs. At least one of the external shafts should be output - mostly two or all the three. The transmission enables required output shaft speed without high cost ordinary speed control system. However, to achieve the optimal speed (minimum fuel consumption) of prime mover, its speed should be controlled - without affecting the required output speed. Due to inertia of rotating masses, the smooth passing over the different operation conditions is enabled - like in any other CVT. The kinematic synthesis for this novel series of ICTs is demonstrated and their feasibility is proved. Among number of feasible transmissions, one is chosen as a numerical example, applicable in a vehicle with internal combustion engine as prime mover. Its basic design is carried out. It has two output shafts the speeds of which are controlled by control motor. 3-D simulation of the transmission shows the expected behaviour.

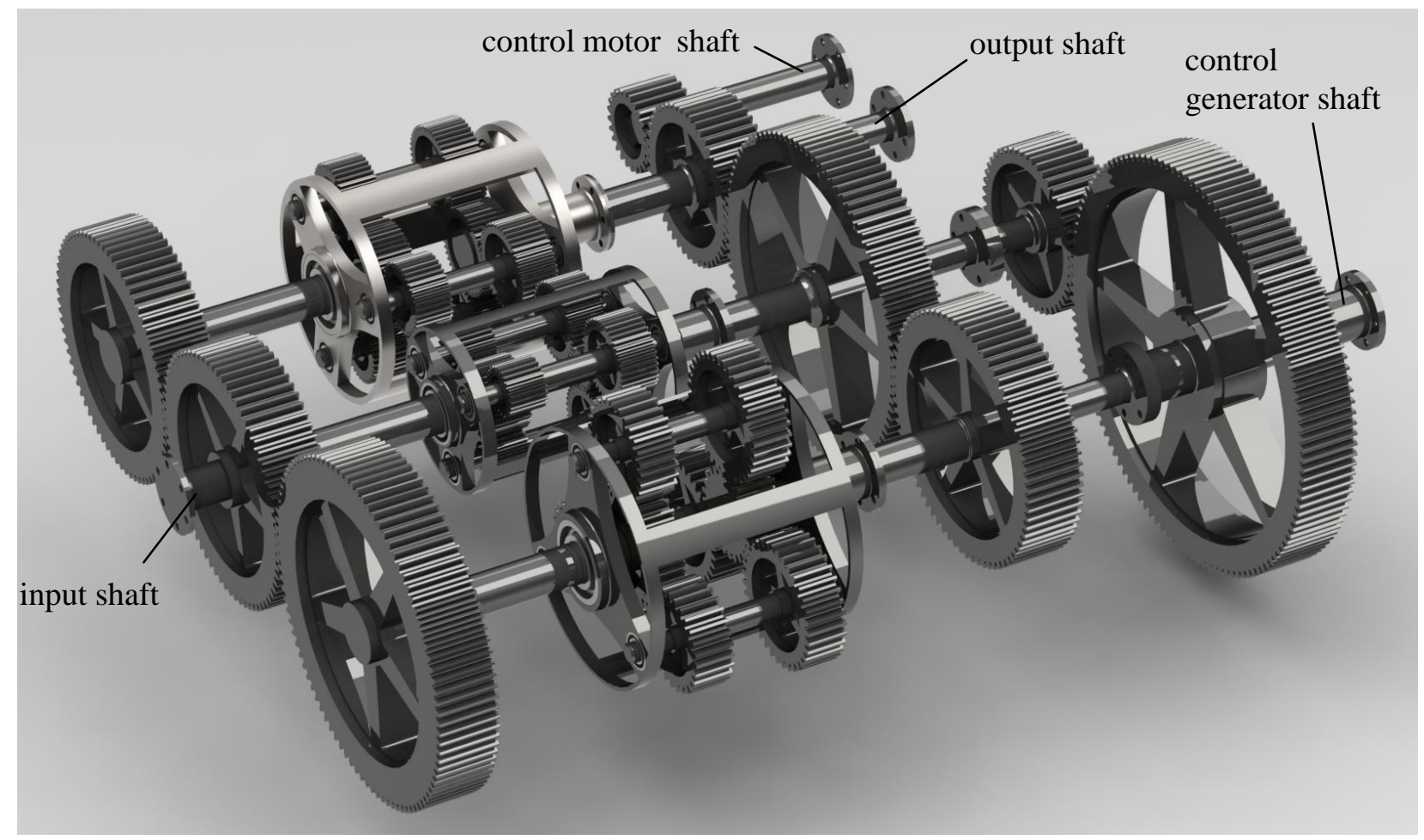

Figure 6. Basic design of animated transmission

Since high efficiency of DGTs can be reached by changing the BGRs of DGTs, and because there is no power consuming friction element as in ordinary CVTs, the efficiency of entire transmission would be high. For efficiencies of an ordinary gear pairs and basic efficiencies of DGTs estimated 0.99 and for neglected ventilation and splash power losses of the carriers with planets, the efficiency of DGTs in our numerical example are easily calculated from expressions in reference [24]: $\eta_{\text {DGT,A }}=$ 0.983 to $999 ; \eta_{\text {DGT,B }}=0.986$ to $0.999 ; \eta_{\text {DGT,C }}=0.98$ to 0.999 , depending on variable transmission ratio. As result of power analysis, we found the transmission efficiency to vary within values of 0.9 at small engine speeds to 0.97 - approximately equal to manual transmissions efficiency.

Further investigation is required to determine the dynamic behaviour of the proposed system in relation to the overall control system design and the behaviour of the electrical components. Test benches and simulation programs for the vehicle power system are planned, in the Power Transmission Laboratory in the Mechanical Engineering Department of the University of Split, Croatia. 


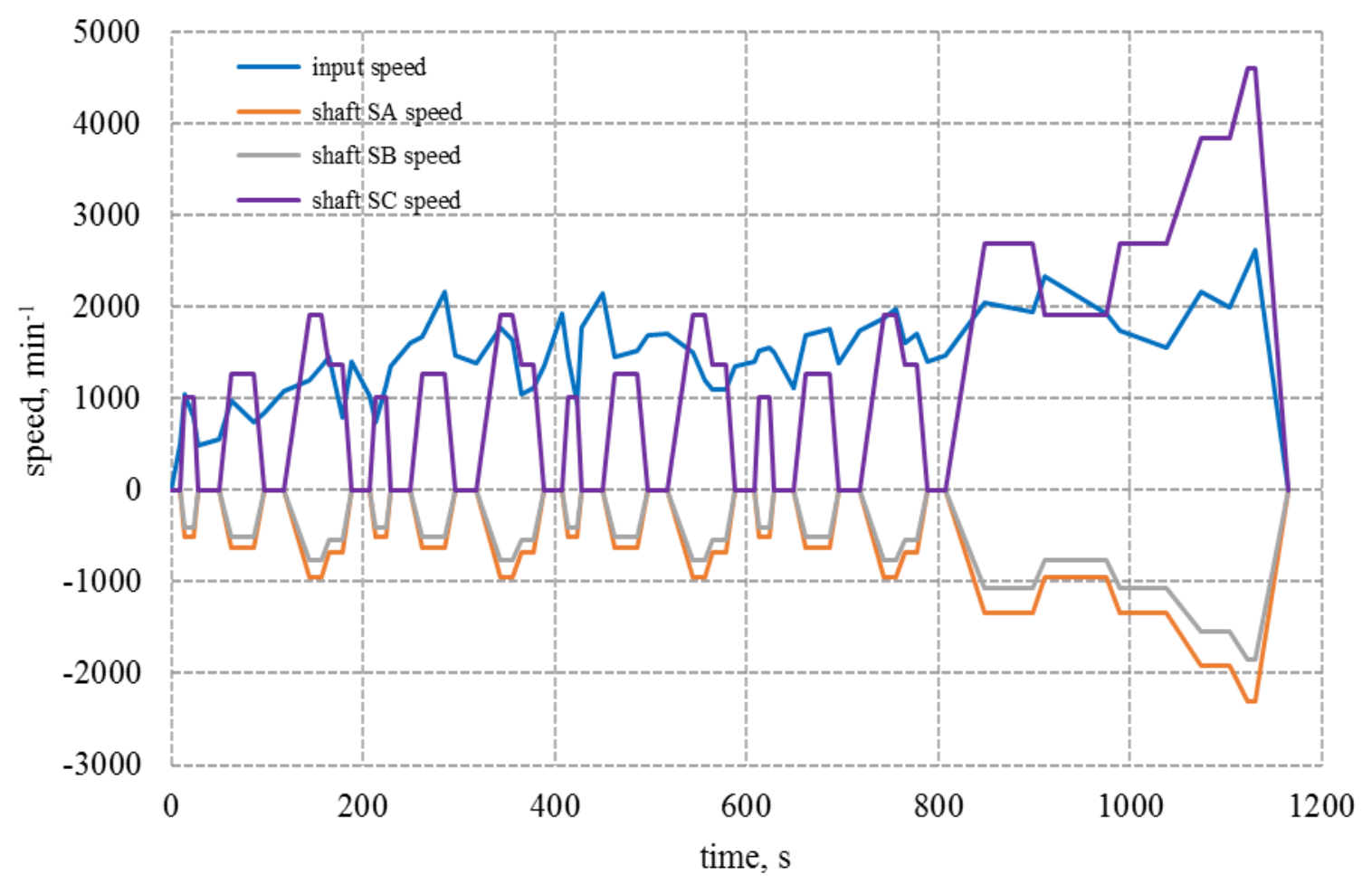

Figure 7. Speed history of the transmission external shafts for standard vehicle testing procedure for randomly chosen input speed variation

\section{Acknowledgement}

The National Science Foundation of Republic of Croatia financially supported this research.

\section{References}

[1] M.S. Kumbhar and D.R. Panchagade, A Literature Review on Automated Manual Transmission (AMT), Int. J. Scient. R \& D. 2 (2014) 1236- 1239.

[2] G. Mantriota, Theoretical and experimental study of a power split continuously variable transmission system Part 1, Proc. IMechE, Part D: J. Automob. Eng. 215 (2001) 837-850.

[3] G. Mantriota, Theoretical and experimental study of a power split continuously variable transmission system Part 2, Proc. IMechE, Part D: J. Automob Eng. 215 (2001) 851-864.

[4] V.H. Mucino, Z. Lu, J. E. Smith, M. Kimcikiewicz and B. Cowan, Design of continuously variable power split transmission for automotive applications, Proc. IMechE, Part D: J. Automob Eng. 215 (2001) 469-478.

[5] N. Srivastava and I.U. Haque, A review on belt and chain continuously variable transmissions (CVT): Dynamics and control, J. Mechanism and Machine Theory. 44 (2009) 19-41.

[6] T. Kim and H. Kim, Performance of integrated engine-CVT control considering powertrain loss and CVT response lag. Proceedings of IMechE, Part D: J. Automob. Eng. 216 (2002) 545-553.

[7] N. Srivastava, I.U. Haque, On the operating regime of a metal pushing V-belt CVT under steady state microslip conditions. In: 2004 Intern. Contin. Variable and Hybrid Transmission Congress, Paper No. 04CVT-11 (2004-34-2851), San Francisco, USA, September 23-25, 2004.

[8] J. Kim, F.C. Park, Y. Park and M. Shizuo. Design and analysis of a spherical continuously variable transmission. ASME Journal of Mechanical Design. 124 (2002) 21-29.

[9] H.S. Jeong and K. Lee, Shift characteristics and smooth shift for an automatic power transmission. Korean SME Int. J. 14 (2000) 499-507. 
[10] R.P.G. Heart and A.J. Child, Zeroshift automated manual transmission (AMT), SAE paper No. 2007-26-061, (2007) 693-696.

[11] T. Burton, D. Sharpe, N. Jenkins and E. Bossanyi, Wind Energy Handbook, John Wiley and Sons, Chichester, UK, 2011.

[12] P. Jamieson, Innovation in Wind Turbine Design, John Wiley and Sons, Chichester, UK, 2011.

[13] L. Idan, and D. Lior, Continuously variable speed wind turbine: transmission concept and robust control, Wind. Eng. 24 (2000) 151-167.

[14] R.J. Hicks, F. Cunliffe and U. Giger, Optimised gearbox for modern wind turbines, In: Proc. EWEC Conf., London, 24-27 November 2004.

[15] X. Zhao and P. Maißer, A novel power splitting drive train for variable speed wind power generators, Renew. Energy 28 (2003) 2001-2011.

[16] H. Müller et al. Grid compatibility of variable speed wind turbines with directly coupled synchronous generator and hydro-dynamically controlled gearbox. In: $6^{\text {th }}$ Int. Workshop on Large-Scale Integration of Wind Power and Transm. Networks for Offshore Wind Farms, Delft, October 2006.

[17] J.R. Gomà Ayats, U. Diego-Ayala and F. Fenollosa Artes, The singular point transition concept: A novel continuously variable transmission comprising differential gear trains and a variator, J. Power Sources. 197 (2012) 125-135.

[18] G. Mantriota, Performances of a series infinitely variable transmission with type I power flow, Mechanism and Machine Theory. 37 (2002) 579-597.

[19] G. Mantriota, Power flows and efficiency in infinitely variable transmissions, Mechanism and Machine Theory. 34 (1999) 973-994.

[20] D. Jelaska, S. Podrug and M. Perkušić, A novel hybrid transmission for variable speed wind turbines, Renewable Energy. 83 (2015), doi:10.1016/j.renene.2015.04.021.

[21] G.S. Hwang, D.M. Tsay, W.H. Liao, J.H. Kuang and T.L. Chern, Kinematic Analyses of a Parallel-type Independently Controllable Transmission, Int. J. Autom. Smart Technol. 1 (2011) 87-92.

[22] G.S. Hwang, D.M. Tsay, W.H. Liao, J.H. Kuang and T.L. Chern, Power Flows and Torque Analyses of an Independently Controllable Transmission with a Parallel Type, In: Proc. World Congress on Engineering, Vol III, London, 6-8 July 2011.

[23] D. Jelaska, Gears and Gear Drives, John Wiley and Sons, Chichester, UK, 2012.

[24] H.W. Müller, Epicyclic Drive Trains, Wayne State University Press, Detroit, US, 1982. 